beacons erected near the terminal points was found to be of great service. Over the central part of the course signals from both beacons could be heard, and it was estimated that at the distance of 1200 miles from Honolulu the width of the equi-signal zone was about eight miles, which indicates that the zone employed was unusually sharp (about $0 \cdot 4^{\circ}$ ).

Some experiments carried out at an altitude of 2000 feet and described by H. Pratt indicate that at night the radio beacon system may be subject to erratic shift of the beacon course when the distance of transmission exceeds some fifty miles. In general, the changes in direction observed were less than $25^{\circ}$, but they were considered sufficiently serious to make the further study of this phase of the subject an urgent necessity. Apparently the errors are much reduced in magnitude by the use of a vertical antenna in the aeroplane, but this does not effect a complete cure and there will possibly be a limited range, of the order of about a hundred miles, over which this type of beacon may be considered to give results of the highest accuracy.

According to a recent publication, ${ }^{8}$ the Airways Division of the U.S. Department of Commerce proposes to build fifty directive radio beacons of the aural signalling type in addition to the nine such stations already in operation. These beacons will all operate on a wave-length band 950 -1050 metres (285-315 kilocycles per second) allotted by international agreement to beacon stations, and will be located along the main air routes at distances apart not exceeding 200 miles. In addition, these routes will be equipped with the low power non-directional
' marker' beacons which will give an aural signal to the pilot for a period of one or two minutes as he is flying overhead. These ' marker' beacons serve to inform the pilot as to his exact position along the course, and also to give him any local weather reports or other information of importance to the navigation of aircraft along the route in question.

Simultaneously with the development of these beacons special receiving equipment has been developed for use on the aeroplane. These receivers are designed to be sufficiently sensitive to work from the $6 \mathrm{ft}$. vertical aerial standardised for the aeroplane, and to give sufficient output for use with either the aural or visual methods of indication. Attention has been devoted to reducing the weight of the whole receiving equipment to the absolute minimum. It is likely that in the near future all mail and passenger carrying aeroplanes in the United States of America will be equipped with such receivers in order to make use of the extensive scheme of beacons now being erected for the specific purpose of assisting the navigation of aircraft.

${ }^{1}$ E. Buchwald : “Scheller"s Wireless Route Indicator Applied to Aeroplanes". Jahrbuch. d. drahtl. Tel., vol. 15, pp. 114-122; 1920. 2 F. Kiebitz: "New Experiments with Scheller's Directional Transmitter". Ibid. pp. 299-310.

${ }^{3}$ F. H. Engel and F. W. Dunmore: "A Directive Type of Radio Beacon and its Application to Navigation ". Scientific Paners, Bureat of Standards, vol. $19, \mathrm{pp} .281-295 ; 1924$

4. H. Dellinger and H. Pratt': "Development of Radio Aids to Air Navigation". Proc. Inst. Radio Eng., vol. 16, pp. 890-920; 1928 5 J. H. Dellinger and H. Diamond: "Radio Developments Applied to Aircraft". Aeromautical Eng., pp. 57-66;1929.

B F. G. Kear and W. G. Jackson: "Applying the Radio Range to the Airways". Proc. Inst. Radio Eng., vol. 17, pp. 2268-2282 ; 1929. "C. C. Shangraw: "Radio Beacons for Transpacifle Flights". Proc. Inst. Radio Eng., vol. 16, pp. 1203-1235; 1928.

sadio News, April 1930, p. 906 .

\title{
The Second World Power Conference at Berlin.
}

$\mathrm{T}$ HE Second Plenary World Power Conference which was held at Berlin on June 16-26 was probably one of the most ambitious and one of the most elaborately staged international meetings of recent years, and it is difficult on that account to follow with accuracy the main lines of development which were traced throughout the discussions. In the first place, the weight of documentary material was very large. Prior to the opening of the Conference, about 390 papers submitted by 37 or 38 countries had actually been printed and were available for examination; but during the Conference itself a number of additional papers appeared, mostly from Germany and Austria, with the result that the official collection will probably be rather more than 430 . In addition to that, the principal scientific and technical associations in Germany and Austria, and, to some extent also, Russia, had prepared special monographs surveying the position in their respective territories. These monographs did not form an intrinsic part of the Conference, but they should be considered as an additional contribution to the information collected.

The delegates and members assembled at the various sessions totalled about 3900 , while the papers were divided into 34 main sections corresponding roughly to the main aspects of national and international power development. During each full day six of these sections came up for examination at six meetings and the average number of speakers lay between 20 and 25, with, in certain cases, more than 30 taking part in the discussions. In all, therefore, during the period of the Conference, more than 1000 actual contributions were made to the work of assessing and judg. ing the material submitted. These statistics are necessary to a comprehension of what might have been and what was actually achieved. In no case did discussion elicit any new information of value or record experiences which were not already described in the papers themselves, and, if one were able to bring the discussions into line with the actual documents, one would find considerable duplication and little real originality.

The importance of the Conference lay, therefore, not so much in any survey of the international power situation it attempted, as in the work of direct personal co-operation which took place unofficially before and after the Conference meetings. It also served to illustrate the reality of the industrial recovery which has taken place in Germany since 1924, since one important feature was the very extensive series of visits to German industrial works which was staged during and after the Conference. It is unnecessary to touch on this

No. 3168 , Vou. 126] 
side of its activities since the process of rationalisation and re-equipment of industry in Germany has been followed with great care by economists and by technical experts in Great Britain, and has already been fully recorded.

The Berlin Conference afforded an opportunity for discussion of the achievements of engineers from the principal industrial countries, and some decisions of value regarding British industry may well emerge from it.

The organisers of the Conference worked on a definite plan. They appreciated quite clearly the need for some degree of guidance throughout the complicated mass of material and arranged accordingly. 'Thus, the original papers were summarised in general reports extending to about 3000 words each. These reports numbered 34, were prepared each by a German engineer or industrialist, and they indicated what were the broad lines of progress and what were the most urgent questions still to be examined. In addition to this work of simplification, the main points of policy and of international progress were covered in a series of seven addresses arranged by the principal countries participating. 'Thus in the purely scientific sphere must be placed the addresses of Prof. Albert Einstein and Sir A. S. Eddington; in the purely administrative and economic those of 1)r. Serruys on rationalisation and its latest forms, and Dr. Oskar Oliven on the Central European main transmission zone; in research considered generally the speech delivered by $\mathrm{Mr}$. H. Foster Bain on the place of minerals in a power sustained world, and perhaps that of Dr. Vallauri on technical and general conditions governing the use of electricity. A seventh address which was due to be delivered by Mr. 1). N. Dunlop, chairman of the International Executive Council, on the function performed by power in the evolution of the world, was not delivered owing to the sickness of its author; and in many ways it is a pity that this address could not be given, since, so far as one can understand from the summary given in advance, it did constitute a broad survey which might have served to have placed the details furnished by the original documents and by the discussions into an ordered design capable of immediate appreciation.

The weakness of this whole arrangement was undoubtedly to be found in the quantity of the original papers submitted, in the lack of uniformity shown by the reporters responsible for summarising those papers in the main sections, and for the lack of synthesis in the general addresses themselves. This observation does not apply to the contributions by Prof. Einstein and Sir A. S. Eddington, but it certainly applies to the remaining four speeches, and, through this circumstance, they had practically no value as a guide to deliberations during the Conference. The result was that the International Executive Committee passed no resolutions referring to the work of the Conference, even when arrangements are being made for a Third Plenary Conference to be held in America in 1936 and there may be a Sectional Conference at Stockholm in 1933-this latter still undecided. One was really unable to select from a mass of conflicting resolutions submitted by various countries any single resolution which would embody one contribution by the Second World Power Conference to the progress of power production and utilisation. 'That in itself is very significant and illustrates the inconclusive nature of the discussions which took place.

It was clear even at Berlin that technical progress in itself is now of less immediate importance than it was, and one felt a vague impression that something should really be done to bring discussions more closely into line with investigation of the real difficulties confronting electrical development and the growth of public utilities. One expert was courageous enough to state that in his opinion we had now reached a definite turningpoint in this whole matter of power expansion. We had advanced so rapidly during the last few years that we had not yet taken the measure of that advance, and, through our inability to take that measure, we were in danger of embarking on unnecessary and costly experiment and of introducing a regime of economic as apart from technical inefficiency.

'This observation can be confirmed, I think, by examination of the papers and to some extent also of the discussions; and the necessity for a real economic assessment of what has been achieved emerged more and more clearly as the Conference went on. One example of what I mean may be given. One German paper described the possibility of transmitting electrical encrgy at 380,000 volts pressure from Scandinavia to Germany. A general address given by Dr. Oliven outlined proposals for a Furopean main-transmission system operating at 400,000 volts. At the present moment those proposals are quite fantastic ; and they are fantastic not because they cannot be translated into practice technically, but because economic and political considerations are such as to rule them out. Fven technically, we have no experience yet of operating conditions on a 380,000 volt circuit. It is in the regime of economies that the greatest obstacles are to be found. The transmission of electrical energy from Scandinavia to Germany would only justify itself if German resources proved themselves inadequate to the power consumption demand of the country, or if the exploitation of such resources were so expensive that it would pay to import electrical energy. It is obvious, however, that Cermany would rather import energy from Switzerland, Austria, and even Italy through Switzerland, where it can tap existing power stations and fairly easily accessible existing power resources, than embark on a costly experiment across the Baltic.

The fundamental economic problems are to be found in the effective co-ordination of electrical power production and the control of the new main transmission systems evolved with the view of ensuring the maximum reliability of service and the maximum reduction in costs. Undoubtedly many technical experiments are being carried out. There was an impressive number of papers describing 
power storage schemes built in Saxony and in the Ruhr, and in a number of European countries. Again, in the city of Berlin itself and in Hamburg, Diesel plants have been built of very large capacities to meet wide fluctuations in demand, in addition to existing steam power plant; while in Berlin again a steam accumulator battery at Charlottenburg has been attached to the peakload station. In the Ruhr again, the gas pool created by the big iron and steel and coke oven plants has been in operation for some time. The technical problem appears, therefore, to be approaching solution; it is the administrative and economic which escapes definition.

There are indications also of a definite reaction against the theory of the big unit. There was less discussion in Berlin of giant power stations and giant power units than of the development of an economic load for such stations and such units. The development of such a load enters, at once, into the economic sphere and is inseparable from the consideration and assessment of the general economic activity ruling in the areas of supply. This brings the supply undertaking at once into touch with national oconomic problems and national economic prosperity.

The Berlin Conference was remarkably weak both in research and pure science contributions and in economic studies. It had a number of papers from the United States dealing with certain phases of power economios, especially in the elaboration of a sound price policy and in the definition of the various types of load, industrial or otherwise. But to give only one indication of what had become really urgent; the Conference failed to touch, even indirectly, on the following :

Whether it is more econornic to close down fairly efficient medium-sized generating stations, aged ten years or more, none of which are being operated on a base load within an interconnected system, and build new stations with Diesel engines, or similar plant capable of interrupted operation without serious loss of efficiency?

The question here bears on depreciation factors, on the relation between the capitalised value of efficiency and the capital loss incurred by the closing down of such power stations and on the distribution of costs within the interconnected network itself. This is not a matter for mere calculation, it is really a matter for a genuine survey of the industrial and other potentialities of the area of supply. It is in the last degree the first movement towards a genuine economic assessment. The Conference made no effort to examine the problems in research advanced by C. F. Hirschfield in his paper " Research relating to Power Development" and avoided discussion of broad questions of industrial efficiency, rationalisation, and competitive efficiency based on power.

One outstanding requirement was really the coordination of essential information; while, at Berlin, statistical surveys of power resources were not given in any great number, owing to the general impression that preceding conferences had covered this side fairly adequately, yet there was almost a complete lack of statistics bearing on the utilisation of electricity, on the various types of power consumption, and on national productive capacity, measured with reference to power. One or two papers touched on this question tentatively; but this field is almost wholly virgin and requires to be cultivated before the next important forward movement can take place.

We are coming to the end of what might be regarded as a technical cycle and entering on the economic cycle. But, whereas in the case of the technical cycle, some background had actually been established merely through the process of evolution, no such background is available in the economic sphere. It may be objected that the general economic principles governing power production and consumption have not yet been formulated, and until they are formulated effective discussion of economic data is really impossible; but in the technical sphere the broad principles along which development is now taking place were not formulated in the first place. They were defined by purely empirical means and resulted from material experience. It was merely a case of trial and error.

The World Power Conference should find in the economic cycle its most valuable and most effective source of activity, and it should concentrate on this to the exclusion of almost everything else. It should examine all the possibilities of assessment on an economic basis; examine all the factors which govern the cconomic expansion of power production and consumption and link it up with general international industrial activity. It should aim at the standardisation of statistical forms and arrange for the exchange of essential data, drawn up in such a way that international comparisons can be carried out without difficulty.

Hugh Quigrey.

\section{The Bristol Meeting of the British Association.}

\section{Local Arrangements.}

N interval of thirty-two years has passed A since the British Association last met in Bristol. The 1930 meeting on Sept 3-10 under the presidency of Prof. F. O. Bower will be held in that city under conditions differing in many respects from those of the year 1898. In 1898 there was no Cniversity of Bristol and the Sections were housed in a scattered variety of buildings adapted for the purpose. Since that time, however, through the munificence of the Wills family, the Cniversity can provide within its walls accommodation for the reception room and general offices as well as for practically all the Sections. Moreover, the main buildings as architectural features form a landmark in the history of provincial universities. 